\title{
An investigation into the factors influencing inter-urban freight mode choice decisions in the Southern African Development Community region
}

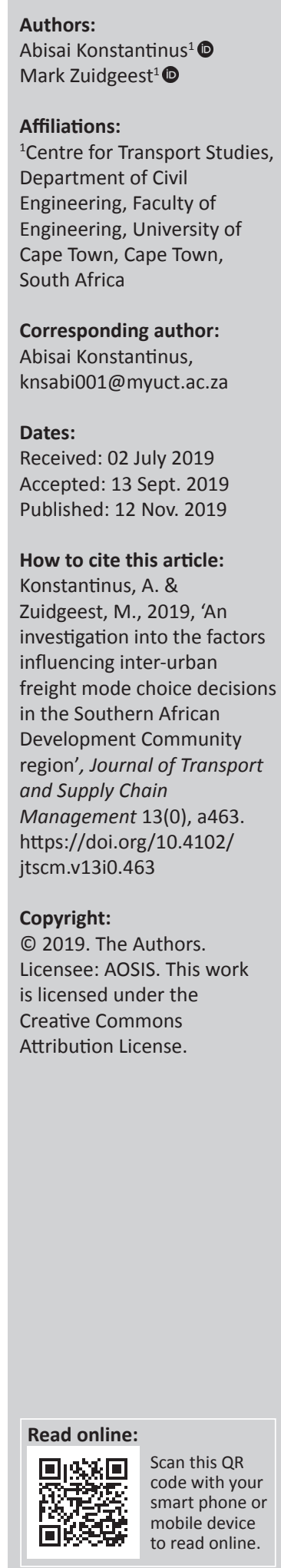

Background: Two recurring issues in freight research regard the determination of the decisionmakers in terms of freight mode choice and the modal attributes that shippers consider when making such mode choice decisions.

Objectives: As few studies have been conducted in freight transport research in the Southern African Development Community (SADC) region; this paper provides empirical results on two research questions that allows the understanding of the freight procurement landscape in SADC. Firstly, who the decision maker is in terms of freight mode choice, and secondly, which modal attributes are consider and in which order, when shippers make mode choice decisions.

Method: An online survey was conducted with 86 shippers, freight forwarders and thirdparty logistics parties across the SADC region to address modal attributes in freight mode choice. The exploded logit model was developed to draw inference from the data.

Results: The results confirm that freight mode choice decisions are mostly affected by the shipper, with the freight forwarder being typically employed as the advisor. In terms of modal attributes, the results of an exploded logit model revealed that the top five attributes in terms of importance are reliability with reference to arriving on time, transport cost, risk of damage, frequency of service and transit time.

Conclusion: These results can inform freight studies, especially shipper behavioural studies, which require the enumeration of attributes that can lead to improved reliable studies on freight transport.

Keywords: exploded logit model; SADC; inter-urban freight; mode choice; Africa.

\section{Introduction}

The Southern African Development Community (SADC) region identified, as a major activator of its developmental objectives, the need to develop a regional freight transport system to achieve social integration, economic development and intra-regional trade (SADC 2013). To realise these ambitions, there is an identified need to conduct empirical studies to support freight transport policies (Konstantinus et al. 2019). Understanding freight transport, however, is not without its challenges. Two particular areas of contention reiteratively occur in the literature: determining the decision-maker (DM) in terms of freight mode choice and determining the modal attributes that shippers consider when making mode choice decisions (Bergantino \& Bollis 2003; García-Menéndez et al. 2004). These issues were first highlighted by Winston (1983) when he researched 'the critical determinants of mode choice in freight transport' in the United States (US). To date, these issues continue to be reiterated in freight transport research (Feo-Valero et al. 2011; Kim, Nicholson \& Kusumastuti 2014).

The confusion is not unfounded as freight transport decisions are generally complicated by the wide range of issues which confront the DM (Konstantinus \& Zuidgeest, 2018). For instance, shipper characteristics such as nature of business, size and structure of the company and location of business activities all influence transport requirements (Rodrigue 2017:127). Moreover, there is an increasing prominence of third party logistics (3PL), which is driven by globalisation and technology advancement (Gupta, Ali \& Dubey 2011). The developments have led to greater supply chain integration geographically and at internal and external company levels of shippers (Paixão Casaca \& Marlow 2005). As a result, unlike in passenger travel studies, where the DM is the passenger (who is also the user), the DM in freight transport can be the shipper, receiver or freight forwarder (FF). Fittingly, this article aims to contribute to research on freight transport by addressing these two issues in the SADC context, namely, to determine who the DM is in terms of freight mode choice and to determine the modal attributes that shippers consider when they make decisions regarding a freight mode choice. 
The motivation for this research is rooted in Konstantinus et al. (2019) who conducted a theoretical investigation on developing short-sea shipping as an alternative mode of freight transport in the SADC region. They concluded that there is potential in developing short-sea shipping; however, there is a need for empirical research to better understand the freight procurement landscape in SADC.

The article proceeds as follows: We first review the literature on freight mode choice, discuss the methods employed to collect and analyse the data and then present the sample results, followed by individual analysis of the research questions. Finally, we discuss the results and conclusion of the research.

\section{Literature review}

Literature on freight mode choice is very limited and appears to be exclusive to the context of developed countries. Known research has generally been conducted in New Zealand, Australia and the bigger European and North American regions (see Table 1). The only known paper on freight mode choice in the SADC region is Zamparini, Layaa and Dullaert (2011).

With regard to the DM, most freight studies have employed either shipper or FF depending on who the research team believes really makes the mode choice decisions. For instance, De Jong et al. (2001), in their review of time valuation in freight transport, confirm that shippers are the DMs while FFs are mostly responsible for route selection. Bergantino and Bolis (2003) on the contrary submit that more than half of mode choice decisions are made by FFs, and by implication, therefore, the FF is the DM. This lack of consensus, if not addressed, can have an impact on the outcomes of freight behaviour and associated policy implications. This is primarily because FFs are generally market-oriented, whereas shippers tend to be production-oriented on issues of freight transport (Woxenius et al. 2004).
When it comes to the determination of modal attributes, the methods typically employed include literature reviews, focus group discussions, interviews, unscientific syntheses of previous studies and, sometimes, merely the opinion of the researcher (Arencibia et al. 2015; Feo, Espino \& Garcia 2011; García-Menéndez et al. 2004). The literature review method is generally standard; however, most studies outside Europe still adapt attributes from what is considered standard in the existing corpus of largely European literature (Bendall \& Brooks 2011; Zamparini et al. 2011). A notable example is Zamparini et al. (2011) who employed modal attributes adapted from European literature to study decisions on freight mode choice in Tanzania, a developing country which operates under different circumstances of culture, law and technology. If there is one thing we learn from the long-standing literature on shipper behaviour that spans at least four decades, it is a constantly changing landscape of mode choice attributes (Kim et al. 2014; Murphy \& Hall 1995). This change occurs both across time and geography (Paixão Casaca \& Marlow 2005).

In this study, we determine the DM and the modal attributes in a manner that is both systematic and suitable to a developing economy context such as SADC. The DM in this study is determined by asking respondents to indicate who the DM in their business is, and the modal attributes are determined by asking respondents to rank a number of modal attributes in terms of importance. The attributes were determined from the literature and were further refined by reference to SADC industry reports, newspaper articles, focus group discussions and survey piloting.

\section{Methods}

\section{Survey development and ethics consideration}

Because the overall intention of the study was to develop an understanding of freight transport decisions, the questionnaire included questions that capture descriptive information of the

TABLE 1: List of literature on shipper behaviour.

\begin{tabular}{|c|c|c|c|}
\hline Author & Region & Modal attributes & DM \\
\hline Jiang, Johnson and Calzada (1999) & Europe & Frequency, distance and shipment size & Shipper \\
\hline Zachcial (2001) & Europe & Cost and distance & Shipper \\
\hline Bergantino and Bolis (2003) & Italy & Cost, time, reliability and frequency & $\mathrm{FF}$ \\
\hline García-Menéndez et al. (2004) & Spain & Cost, time, damage, distance, delay, frequency and environment & Shipper, FF \\
\hline Brooks et al. (2006) & US, Canada & Reliability, distance and frequency & Shipper \\
\hline Brooks and Trifts (2008) & US, Canada & Reliability, distance and frequency & Shipper \\
\hline García-Menéndez and Feo-Valero (2009) & Europe & Cost, time, reliability and distance & Shipper \\
\hline Puckett et al. (2011) & US, Canada & Reliability, distance, frequency and cost & Shipper \\
\hline Zamparini et al. (2011) & Tanzania & Reliability, cost, transit time, damage, flexibility and frequency & Shipper \\
\hline Feo-Valero et al. (2011) & Spain & Time, cost, reliability and frequency & $\mathrm{FF}$ \\
\hline Brooks et al. (2012) & Australia & Time, cost, reliability and frequency & Shipper, FF \\
\hline Bergantino et al. (2013) & Europe & Time, cost, punctuality and damage & Shipper, carrier \\
\hline Kim et al. (2014) & New Zealand & Time, cost, reliability, frequency and damage & Shipper \\
\hline Russo et al. (2016) & Europe, North-Africa & Time, cost, hub-port and service port & Carrier \\
\hline Meers et al. (2017) & Belgium & Time, cost, reliability and frequency & Shipper \\
\hline
\end{tabular}

DM, decision-maker; FF, freight forwarder; US, United States. 
respondents (i.e. the modes used, respective modal splits that the respondent assigns to each mode employed and questions to capture perceptions on reliability) in addition to questions to determine who the DM is and to obtain a ranking of modal attributes. This article focuses only on the questions of the DM and modal attributes. The other variables of the questionnaire are analysed and presented by Konstantinus and Zuidgeest (2018).

The DM question presented four transport options. From these, the respondents had to identify the DM in their business: the manager in charge of logistics, top management jointly, the FF and others. In addition, respondents were given the option to elaborate further in a follow-up question.

With regard to attribute determination, this was a ranking question, wherein respondents were asked to rank the following modal attributes in terms of importance: frequency of service, transport cost, transit time, reliability in terms of arriving on time, customer service, ability to track and monitor, risk of loss and damage, environmental friendliness and flexibility of model.

When the survey development was completed, ethics clearance was applied for and obtained.

\section{Survey piloting}

Before the survey was hosted, it was piloted in Cape Town with three shippers and one FF. The pilot survey revealed and addressed four major shortcomings in the survey. For starters, respondents added three attributes to the ranking of the attributes question, which we had overlooked: customer service, tracking and monitoring, and environmental friendliness. The inclusion of monitoring and tracking was justified after the pilot survey revealed that SADC shippers appear to be concerned about increased cargo theft and truck hijacking in South Africa (Lowitt 2017). Secondly, the pilot survey revealed that the survey took too long; therefore, we had to shorten it to avoid respondent fatigue. Thirdly, questions on the cost of transport were removed as they were considered sensitive and could potentially discourage participation. Fourthly, in order to reduce bias and satisficing in the ranking question, attributes were randomised to vary between respondents. The final survey was freely hosted with Sawtooth Software, Inc., (Provo, Utah, United States).

\section{Data collection}

To collect data, respondents were required to complete an online survey. The online survey method is said to be cost and time efficient in terms of collecting large amounts of data from a large number of geographically dispersed respondents; however, it often suffers from low response rates (Punch 2014). Accordingly, in order to obtain a big enough and representative sample, respondents' contacts were first obtained from shipper and FF associations, port authorities and web databases, and then a stratified sample of 1500 respondents was populated, with at least 50 respondents selected per SADC member country. Subsequently, additional efforts were made to have a wide distribution of respondents between business sectors, company sizes and product type. To encourage respondents to participate, they were first invited by email, followed by telephone calls between November 2016 and March 2017. To improve the survey response rate, recipients were reminded via email to complete the survey every $2-3$ weeks until the deadline of the survey (i.e. 30 March 2017).

\section{Modelling}

\section{Testing for difference in distribution of categorical variables}

To test for the difference in the distribution of categorical variables, and to assess tests of independence between two or more categorical variables, most commonly Pearson's chisquared test is employed. This is done by comparing the observed pattern of responses to the pattern that would be expected if the variables were truly independent of each other. The test statistic is calculated as shown in Equation 1, and compared against a critical value from the chi-square distribution (Diener-West 2008). This allows the researcher to assess whether the observed cell counts are significantly different from the expected cell counts.

$\chi^{2}=\sum \frac{(\text { Observed }- \text { Expected })^{2}}{\text { Expected }}$

where the term 'Observed' refers to the observed frequency and 'Expected' refers to the expected frequency.

\section{The exploded logit model}

The exploded logit (EL) model is employed to model the preference of individuals for ranked data items, where a set of choices is ranked by the same respondent (Skondral \& Rabe-Hesketh 2003). The framework of the EL model is based on decision field theory (Hess \& Palma 2019:35). A key assumption in decision field theory is that the preferences for alternatives update over time. Accordingly, the DM is said to consider all the alternatives until an internal threshold is reached (similar to the concept of satisficing, where one of the options is deemed 'good enough') or some external threshold such as a time constraint, where the DM will stop deliberating on the alternatives as a result of running out of time to make the decisions.

The formulation of the EL model for the observed ranks postulates an underlying utility model. If we consider $A_{n}=\left\{a_{n}^{1}, \ldots, a_{n}^{A_{n}}\right\}$ as the set of $A_{n}$ alternatives available for respondent $n$, then the probability of observed rankings is given by:

$$
P\left(R_{n} \mid A_{n}\right)=\prod_{k=1}^{A_{n}-1} \frac{\exp \left(V_{n}^{r_{i}^{k}}\right)}{\exp \left(V_{n}^{r_{n}^{s}}\right)}
$$

where $R_{n} \equiv\left\{r_{n}^{1}, r_{n}^{2}, \ldots, r_{n}^{A_{n}}\right\}$ is the ranking for respondent $n$ given a set of alternatives, $V_{n}^{r}$ is the deterministic component for unit $b$ and $i$ and $r_{i}^{k}$ are the alternatives given rank $k$.

The model is denoted as 'exploded logit' as the ranking probability is written as a product of first choice probabilities 
for successive remaining alternatives (Skondral \& RabeHesketh 2003). The rankings can be assumed to be obtained successively, such that the best choice is selected first, then the second best among the remaining choices, and so on. At the $k$-th successive selection step, the contribution to rank 1 takes the form of a multinomial probability with sample size one and number of categories determined by the remaining choices.

\section{Ethical considerations}

Ethical clearance to conduct the study was obtained from the University of Cape Town on 16 May 2017 (clearance number: 7482497).

\section{Results \\ Sample statistics}

The sample was composed of 86 respondents from 11 countries across SADC (see Table 2), including Angola, Botswana, the Democratic Republic of Congo (DRC), eSwatini (previously Swaziland), Malawi, Mozambique, Namibia, South Africa, Tanzania, Zamibia and Zimbabwe (Figure 3, 4 and 5). Respondents also varied in terms of industry serviced, type of DM, respondent position and company size.

TABLE 2: Sample statistics.

\begin{tabular}{|c|c|c|c|}
\hline Attribute & Characteristics & Count & $\%$ \\
\hline \multirow[t]{3}{*}{ Type of decision-maker } & Shipper & 32 & 37 \\
\hline & Freight forwarder & 26 & 30 \\
\hline & Other: 3PL/agent & 28 & 33 \\
\hline \multirow[t]{4}{*}{ Level in company structure } & Junior level & 9 & 10 \\
\hline & Supervisory level & 7 & 8 \\
\hline & Manager level & 47 & 55 \\
\hline & Director level & 23 & 27 \\
\hline \multirow{5}{*}{$\begin{array}{l}\text { Company size in terms of number of } \\
\text { employees }\end{array}$} & $1-20$ & 43 & 50 \\
\hline & $21-50$ & 8 & 9 \\
\hline & $51-99$ & 11 & 13 \\
\hline & $100-500$ & 10 & 12 \\
\hline & $500+$ & 14 & 16 \\
\hline \multirow[t]{11}{*}{ Country of residence } & Angola & 6 & 7 \\
\hline & Botswana & 1 & 1 \\
\hline & DRC & 4 & 5 \\
\hline & eSwatini & 1 & 1 \\
\hline & Malawi & 4 & 5 \\
\hline & Mozambique & 2 & 2 \\
\hline & Namibia & 32 & 37 \\
\hline & South Africa & 24 & 28 \\
\hline & Tanzania & 4 & 5 \\
\hline & Zambia & 2 & 2 \\
\hline & Zimbabwe & 6 & 7 \\
\hline \multirow[t]{9}{*}{ Industry serviced } & Retail & 10 & 12 \\
\hline & Mining & 6 & 7 \\
\hline & Electricity & 2 & 2 \\
\hline & Engineering & 29 & 34 \\
\hline & Fisheries & 2 & 2 \\
\hline & Agriculture & 8 & 9 \\
\hline & Manufacturing & 13 & 15 \\
\hline & Tourism & 2 & 2 \\
\hline & Other & 13 & 15 \\
\hline Total number of respondents & & 86 & 100 \\
\hline
\end{tabular}

3PL, third party logistics; DRC, Democratic Republic of Congo.
Because of the time-intensive nature of collecting freight data, as well as the monetary expenses involved in contacting the respondents, it was not feasible to collect data from all countries (Figure 5). The low response rate of 86 out of 3000 reiterated invitations was not surprising because this shortcoming is inherent in many freight studies (Brooks et al. 2008; Feo-Valero et al. 2011). Respondents from the DRC and Mozambique indicated a language barrier and as a result participation was low from these countries.

With regard to the DM variable, the summary of results is presented in Figure 1. As shown in the figure, most respondents $(68 \%)$ indicated that mode choice decisions are taken either by the manager in charge of logistics (34\%) or by the top management jointly (34\%), with $22 \%$ and $10 \%$ indicating $\mathrm{FF}$ and other respectively.

The attribute ranking question was a drag and drop ranking question whereby respondents were asked to rank the attributes from first to least - first being important and ninth being the least important. The summary results of this question are presented in Figure 2. Within the grids of Figure 2, the number of times an attribute was ranked at a certain rank is shown. Accordingly, we can see that reliability was accorded 17 times with rank 1, transport cost 16 times and transit time 15 times and, least of all, environmental friendliness was accorded 0 times with rank 1. Interestingly, environmental friendliness was ranked ninth a record number of 34 times, meaning that it was overall considered as least important.

\section{So, who is the decision-maker?}

To draw further inference from the data, the DM variable was modified as follows: The attribute levels manager in charge of logistics and top management jointly were clustered together representing the shipper, FF remained as is and 'Other' was changed to 3PL/agent. The reason for changing 'Other' to 3PL/agent is that from the survey, it emerged that some respondents outsource some of their logistics functions to third- and fourth-party logistics. The attribute was then cross-tabulated with company size, business industry and respondent nationality to see how different segments make

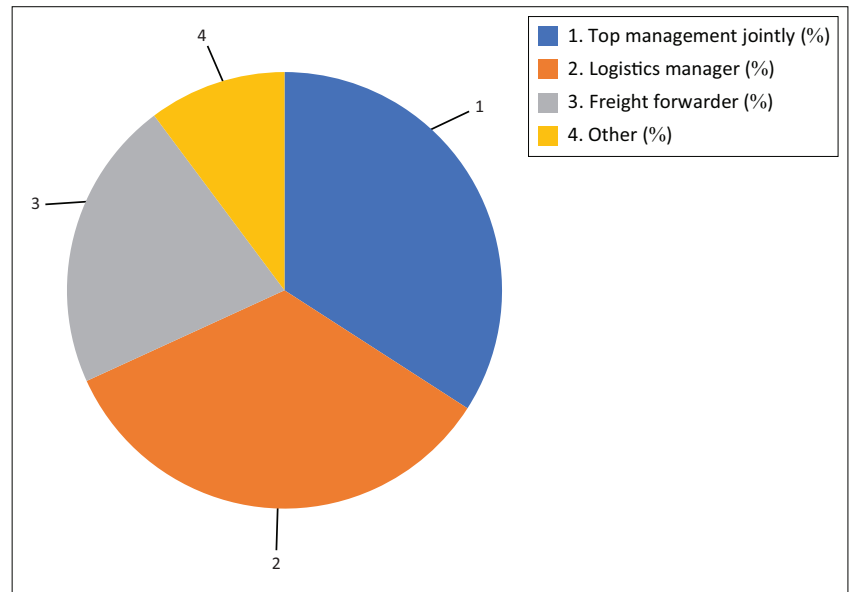

FIGURE 1: Decision-maker in the sample. 
mode choice decisions. The chi-squared $\left(\chi^{2}\right)$ statistic in Equation 1 was subsequently employed to test the hypothesis that the distribution of observation frequencies for the

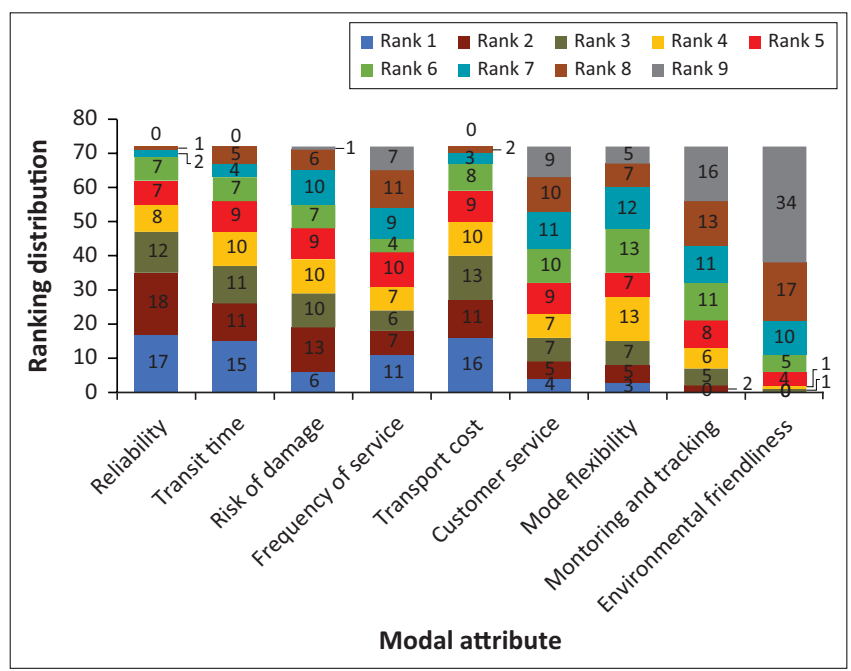

FIGURE 2: Summary of rankings for modal attributes.

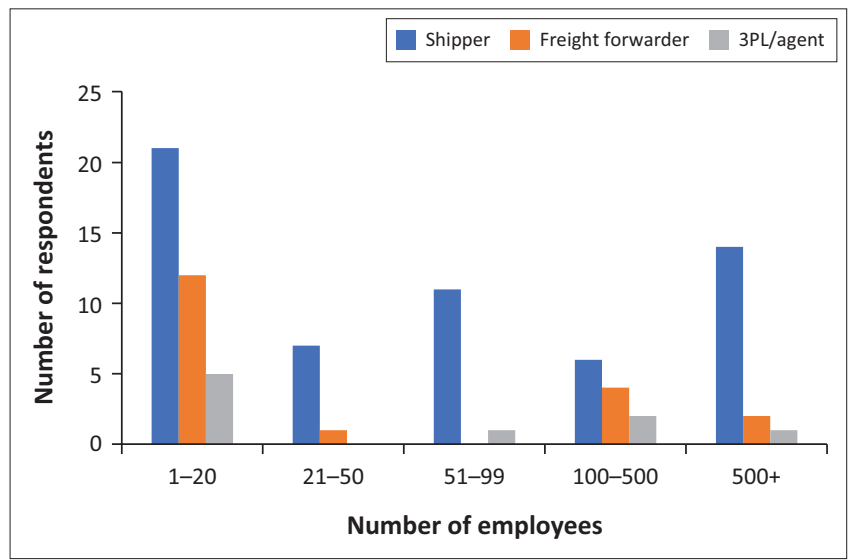

3PL, third party logistics; p.v., $p$-value; $\mathrm{df}$, degree of freedom; $\mathrm{H}_{0^{\prime}}$, hypothesis. Note: $\chi^{2}=46.071, \mathrm{df}=8, \mathrm{p} . v \mathrm{.}=2.304 \mathrm{e}-07$, retain or reject $\mathrm{H}_{0}=$ reject $\mathrm{H}_{0}$. FIGURE 3: Decision-maker by company size. different DM options (i.e. for shipper, FF and 3PL) across the different segments is the same.

Fittingly, in all assessed instances, the null hypothesis $\left(\mathrm{H}_{0}\right)$ is that the observed frequencies of DM across segments are the same as the expected frequencies. If the observed and expected frequencies are the same, we expect $\chi^{2}$ to be 0 . If however the frequencies observed are significantly different from the expected frequencies, we expected the value of $\chi^{2}$ to go up. The larger the value of $\chi^{2}$, the more likely it is that the distributions are significantly different. Accordingly, the decision to reject, or fail to reject $\mathrm{H}_{0}$ is based on the $p$-value at the $95 \%$ significance level. Consequently, if the $p$-value is less than or equal to $0.05, \mathrm{H}_{0}$ is rejected, but if the $p$-value is greater than $0.05, \mathrm{H}_{0}$ is not rejected.

Figure 3 shows that the results are grouped into five levels according to company size, a categorical variable. The results show that it is the shipper who mostly makes the decision regarding freight mode choice. This is confirmed by a $\chi^{2}$ statistic of 46.071 and a $p$-value of less than 0.05 , indicating that the distribution of the DM across the different segments is significantly different. Across industry and nationality, the shipper is confirmed as the dominant DM, followed by the FF and then 3PL or agents as indicated by a small proportion of respondents. These results are confirmed by a $\chi^{2}$ statistic of 35.433 and an associate $p$-value of less than 0.05 in terms of the nationality variable, and a $\chi^{2}$ statistic of 76.438 and an associate $p$-value of less than 0.05 in terms of the industry variable. Accordingly, we can conclude that the distribution of who the DM is across the different SADC countries and industries is significantly different as Figures 3 and 5 show.

These results are also confirmed by the follow-up question, where most of the respondents commented that FFs are typically used as advisors and are usually given the power to make mode choice decisions on a selective basis, for instance, when the cargo is urgent or when there is an allocated budget limit.

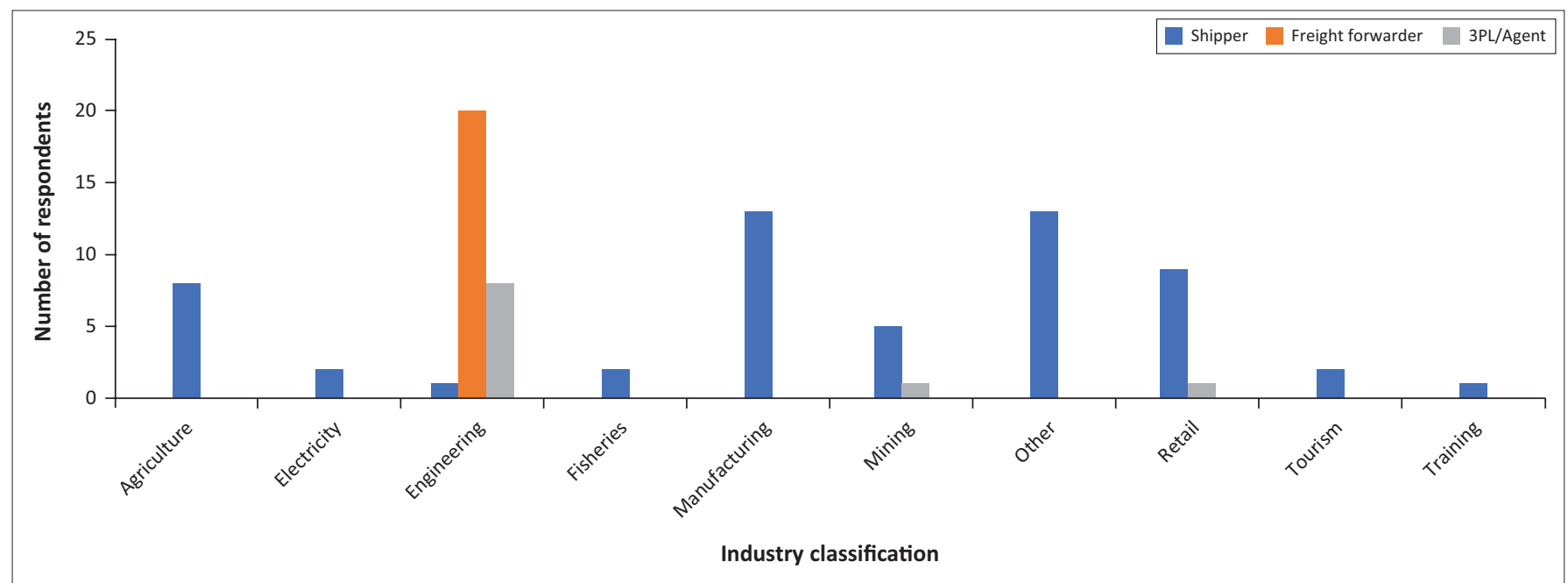

Note: $\chi^{2}=76.438, \mathrm{df}=18$, p.v. $=3.571 \mathrm{e}-09$, retain or reject $\mathrm{H}_{0}=$ reject $\mathrm{H}_{0}$.

$3 \mathrm{PL}$, third party logistics; p.v., $p$-value; $\mathrm{df}$, degree of freedom; $\mathrm{H}_{0^{\prime}}$, hypothesis.

FIGURE 4: Decision-maker by business industry. 


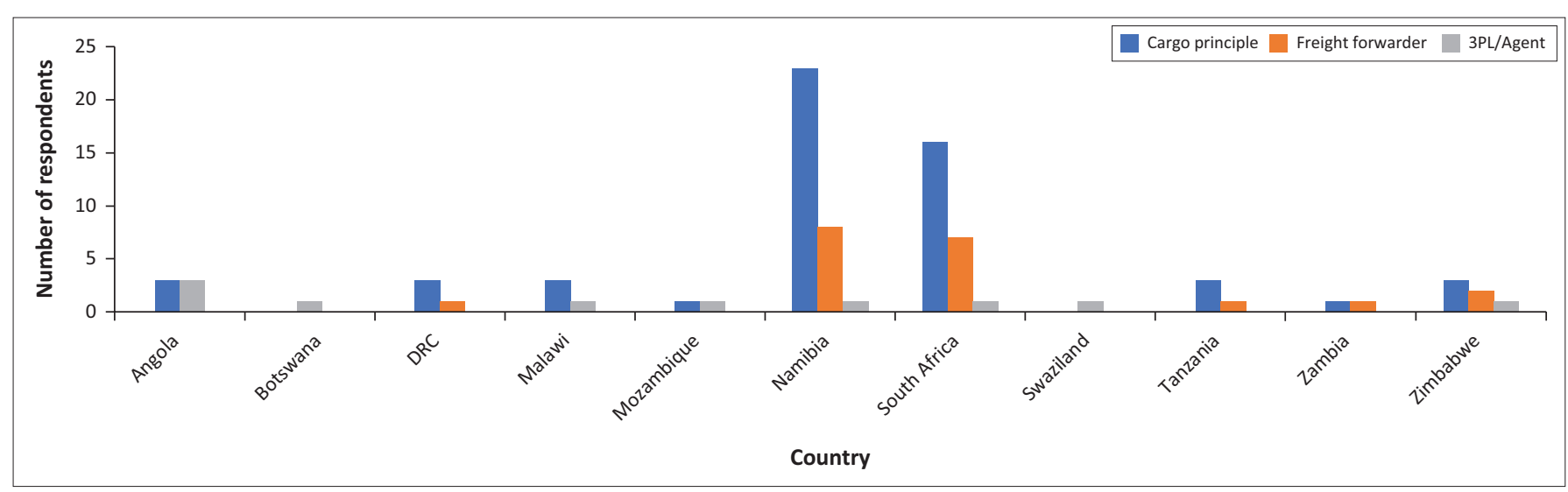

3PL, third party logistics; DRC, Democratic Republic of Congo; p.v., $p$-value; df, degree of freedom; $\mathrm{H}_{0^{\prime}}$ hypothesis.

FIGURE 5: Decision-maker by Southern African Development Community nationality.

\section{What are the significant modal attributes that influence freight mode choice?}

To analyse the results of the ranking of attributes question, the database of the full ranking of modal attributes was arranged in such a way that it presents both the aggregate rankings of attributes per rank and attribute per individual ranking for every observation (see Appendix 1 for presentation of the reliability for the first three respondents). This allowed us to determine the extent to which a certain rank score was contributed by a certain attribute and vice versa. The data set was used to seed the EL model which was specified in R ( $\mathrm{R}$ Core Team 2013), and estimated using the Apollo package (Hess \& Palma 2019).

In the model specification, the likelihood sequence of observing a certain rank observation was obtained by calculating the probability of observing a certain ranking order as specified in Equation 2. The utility function for alternative $i$ in choice situation $t$ for individual $n$ was accordingly given by:

$V_{i, n t}=\beta_{\text {cost }}\left(\operatorname{cost}_{i, n t}\right)+\beta_{\text {time }}\left(\right.$ time $\left._{i, n t}\right)$

$+\beta_{\text {freq }}\left(\right.$ frequency $\left._{i, n t}\right)$

$+\beta_{\text {rel }}\left(\right.$ reliability $\left._{i, n t}\right)$

$+\beta_{\text {customer }_{\text {sevvice }}}\left(\right.$ customer $\left._{\text {customer }_{i, n t}}\right)$

[Eqn 3]

$+\beta_{\text {env }_{\text {friendliness }}}\left(\operatorname{env}_{\text {friendliness }_{i, n t}}\right)$

$+\beta_{\text {flexibility }}\left(\right.$ flexibility $\left._{i, n t}\right)$

$+\beta_{\text {monitoring }}\left(\right.$ monitoring $\left._{i, n t}\right)+\varepsilon_{n s j}$

where $\beta_{r e l}$ is set as a reference attribute in the utility function.

Accordingly, the results of the EL model are presented in Table 3, with the scale parameter capturing the distance between ranks and the parameter coefficients capturing the aggregate ranking for each respective attribute.

We start model interpretation by reviewing the model statistics. As there was no base to compare the model goodness of fit (cf. Train 2009), the first method was to
TABLE 3: Ranking of attributes: Results of the exploded logit model.

\begin{tabular}{|c|c|c|c|}
\hline Variable & Coefficient & r.s.e. & r.t.r. \\
\hline \multicolumn{4}{|l|}{ Attribute } \\
\hline B_Reliability & 0 & NA & NA \\
\hline B_Transit_time & -0.8759 & 0.7928 & -1.1 \\
\hline B_Damage_risk & -0.6127 & 0.6909 & -0.89 \\
\hline B_Service_frequency & -0.6202 & 0.5114 & -1.21 \\
\hline B_Transport_cost & -0.557 & 0.5422 & -1.03 \\
\hline B_Customer_service & -1.1174 & 0.6761 & -1.65 \\
\hline B_Flexibility & -1.5745 & 0.8029 & $-1.96 *$ \\
\hline B_Monitoring & -2.4492 & 1.1224 & $-2.18^{*}$ \\
\hline B_Environmentally_friendly & -3.9027 & 1.7001 & $-2.3 *$ \\
\hline Scale_2 & 0.4106 & 0.3442 & 1.19 \\
\hline Scale_3 & 0.5418 & 0.407 & 1.33 \\
\hline Scale_4 & 0.7017 & 0.336 & $2.09 *$ \\
\hline Scale_5 & 1.0246 & 0.469 & $2.18 *$ \\
\hline Scale_6 & 0.734 & 0.3746 & $1.96 *$ \\
\hline Scale_7 & 0.9798 & 0.4143 & $2.36^{*}$ \\
\hline Scale_8 & 1.035 & 0.5004 & $2.07^{*}$ \\
\hline \multicolumn{4}{|l|}{ Model statistics } \\
\hline LL(start) & -1100.9571 & - & - \\
\hline LL(final) & -949.0692 & - & - \\
\hline Rho-square (0) & 0.1380 & - & - \\
\hline Adj.Rho-square (0) & 0.1243 & - & - \\
\hline AIC & 1928.14 & - & - \\
\hline $\mathrm{BIC}$ & 1964.95 & - & - \\
\hline
\end{tabular}

NA, not applicable; r.s.e., robust standard error; r.t.r., robust $t$-ratio; AIC, Akaike Information Criterion; BIC, Akaike and Bayesian Information Criterion.

$*, p \leq 0.05$.

compare the log-likelihood improvement between the start log-likelihood and the final log-likelihood. The model yielded a final log-likelihood of -949.07 from a start log-likelihood of -1100.96, indicating a good job done by the model. The covariance and correlation matrices are shown in Table 2-A1 and Table 3-A1, respectively.

Subsequently, the interrogation of the magnitude of the parameter estimates gives an indication of the attribute rankings. According to the results, the attributes are ranked in the following order of importance: reliability, transport cost, risk of damage, frequency of service, transit time, customer service, service flexibility, monitoring and environmental friendliness. The parameter estimates for transit_time, damage_risk, service frequency and transport_cost were, however, insignificant, yielding robust $t$-ratios below the $90 \%$ confidence interval. 


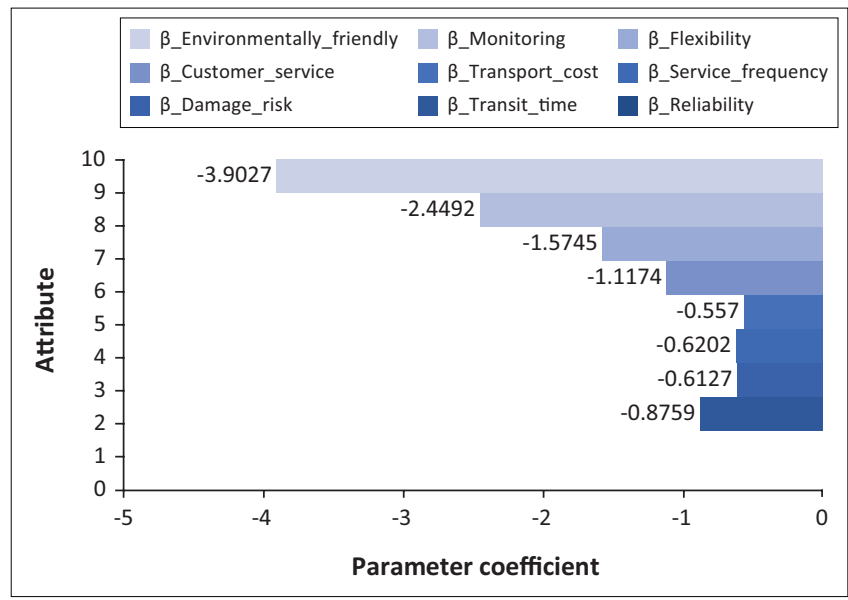

FIGURE 6: Graphical presentation of attribute rankings.

The coefficients for scale_4 and scale_5 to which transport_cost and service_frequency were pegged, however significant, showed a sign of significant differences between ranks 4 and 5. This relationship is further shown in Figure 6, which provides a graphical presentation of the attribute rankings. Similar to the results in Table 3, all the attributes in Figure 6 are presented with reference to reliability (which in Figure 6 has a coefficient of zero).

The ranking of reliability as the most important parameter and environmental friendliness as the least important is consistent with a number of freight studies performed around the world, including India (Mitchell 2005), Europe (Zachcial 2001) and New Zealand (Rockport et al. 2009). This is substantiated in SADC by Ragoobur (2008) who reported that unreliability and inefficiency in transport networks form a major obstacle to doing business within SADC. The ranking of environmental friendliness as the least important variable goes to show that the pressure of environmental values is not yet great enough to affect the decisions of shippers within the SADC region.

The ranking of transit time as the fifth most important attribute behind frequency was however not expected, seeing that transport modes with long transit times tend to be unattractive, as shippers are continuously reducing their lead times to reduce carrying costs and streamline operations to improve productivity (cf. Rodrigue 2017:130). Indeed, the majority of shipper behavioural models have incorporated transit time as one of the most important attributes (see Table 1). Flexibility, which refers to the number of impromptu shipments executed within a short space of time or the ability to adapt to external incidents or changes in customer requirements, has often come out as important but not usually more important than transit time (Zamparini et al. 2011). Flexibility is generally an implicit attribute considered by shippers, such that it does not always come out strong in quantitative studies. Transit time on the other hand is a tangible attribute. A reduction in travel time in a freight transport setting opens up avenues for shippers to concentrate their production and supply chain processes in fewer locations, and to deploy tighter schedules while extending the geographical dimensions of their markets. However, by ranking reliability as the most important attribute, respondents would have assumed that they had taken care of the time component.

Finally, the ranking of damage risk as the third most important attribute was expected, particularly because instances of cargo theft have increased in some parts of the region (Lewitt 2017). In South Africa, for instance, there has reportedly been a $30 \%$ increase in inter-urban freight truck hijackings in 2016 (Ctrack 2017; Pieterse 2018). The thieves are reported to use high levels of violence, and they target both high and low value cargo (Pieterse 2018). Therefore, the incorporation of loss and damage (or cargo safety) as an attribute in freight mode choice could be beneficial in future studies on freight demand.

\section{Discussion}

Notwithstanding the conclusion that the shipper is the dominant DM in terms of freight choice, the analysis of the $\mathrm{DM}$ variable reveals that the FF is not to be ignored as a substantial number of respondents indicated that the FF is assigned the task on a fair number of times. In this regard, Woxenius et al. (2004) confirm that FFs should be consulted in setting the requirements on freight transport because they control large freight flows, they act as proxies for multiple shippers and they have structured consolidated networks with strict time requirements, which make them extremely knowledgeable about freight flows (Woxenius et al. 2004).

With regard to the ranking of attributes, the ranking of reliability as the most important is a key point as reliability is closely related to resilience, which in transport refers to the ability of a transport system to withstand negative incidents and still remain operational to a certain level (Taylor \& D'Este 2003). The implication of this is that the impacts of strategies to improve the levels of reliability are most severe on transport systems that must develop capabilities to respond effectively to the challenges of rail and short-sea shipping.

Moreover, although it is common for businesses nowadays to make decisions based on the environment and society, and even customers tend to prefer to support companies that are sustainable, the ranking of environmental friendliness as least important shows that when it comes to the question of interventions to reduce environmental impact, environmental strategies can only influence mode choice if it is presented as an incentive cost to shippers or as a tax under such as carbon pricing (Bendall \& Brooks 2011; Puckett et al. 2011).

It is further important to note that some modal attributes are random variables, which are subject to variability. Freight interests are constantly changing the way they do business, and the perceptual attributes of transport modes from which they derive maximum utility are constantly changing (Paixão Casaca \& Marlow 2005). For instance, we note that transit time and transport costs both received ranks 1 and 2 a couple of times, which indicates that attribute importance varies between respondents, as shown in the literature (Bendall \& Brooks 2011; Bergantino et al. 2013; Puckett et al. 2011). 


\section{Conclusion}

The need to study freight mode choice in the SADC region is imperative given the strong ambitions to increase intraregional trade. This article looked at two critical, yet often overlooked, issues in freight mode choice. Issues including the identification of the DM and the determination of the modal attributes that influence freight mode choice are critical in understanding freight transport decisions. This is particularly needed in the SADC setting where inter-urban studies on freight mode choice are lacking, and where precedence is yet to be set. From this article, we conclude that the shipper is most often the DM in terms of mode choice in SADC, and the FF occupies a position of advisor. With regard to the most important attributes in terms of mode choice, the top five attributes are reliability, transport cost, risk of damage, frequency of service and transit time, while the least important attribute is environmental friendliness. This information can inform and guide transport policies and future research on shipper behaviour in SADC.

\section{Acknowledgements}

The first author wishes to acknowledge the assistance and support of the Namibian Ports Authority, the Walvis Bay Corridor Group, the Ministry of National Planning of Namibia and Ndatara.com. The authors also wish to acknowledge the extensive assistance of the following organisations that promulgated the surveys to their members: Namibia Logistics Association, Botswana Freight Forwarders Association, the Shipping and Forwarding Agents' Association of Zimbabwe, Walvis Bay Corridor Group (Namibia), the Port Management Association of Eastern and Southern Africa, Transnet National Ports Authority (South Africa), Namibian Ports Authority (Namibia) and Ndatara. com (Namibia).

\section{Competing interests}

The authors have declared that no competing interests exists.

\section{Authors' contributions}

A.K. proposed the research task, planned the study, developed the survey, participated in the interviews, analysed the results and drafted the first version of the manuscript under the supervision of M.Z. Both authors read and approved the final manuscript.

\section{Funding information}

Research funding was in part channelled by the Namibian Ports Authority (Namport), German Academic Exchange Service Namibia, Ndatara.com and the University of Cape Town, Centre for Transport Studies.

\section{Data availability statement}

Data sharing is not applicable to this article as no new data were created or analysed in this study.

\section{Disclaimer}

The views and opinions expressed in this article are those of the authors and do not necessarily reflect the official policy or position of any affiliated agency of the authors.

\section{References}

Arencibia, A.I., Feo-Valero, M., García-Menéndez, L. \& Román, C., 2015, 'Modelling mode choice for freight transport using advanced choice experiments', Transportation Research Part A: Policy and Practice 75(May), 252-267. https:// doi.org/10.1016/j.tra.2015.03.027

Bendall, H.B. \& Brooks, M.R., 2011, 'Short sea shipping: Lessons for or from Australia', International Journal of Shipping and Transport Logistics 3(4), 384-405. https:// doi.org/10.1504/IJSTL.2011.041134

Bergantino, A.S. \& Bolis, S., 2003, An analysis of maritime Ro-Ro freight transport service attributes through adaptive stated preference: An application to a sample service attributes through adaptive stated preference: An application to a sample
of freight forwarders, European Transport I Trasporti Europei, ISTIEE, Institute for of freight forwarders, European Transport Trasporti Europei, ISTIEE, Institute for
the Study of Transport within the European Economic Integration, 25-26, 33-51.

Bergantino, A.S., Bierlaire, M., Catalano, M., Migliore, M. \& Amoroso, S., 2013, 'Taste heterogeneity and latent preferences in the choice behaviour of freight transport operators', Transport Policy 30(November), 77-91. https://doi.org/10.1016/ operators', Transport
j.tranpol.2013.08.002

Brooks, M. \& Trifts, V., 2008, 'Short sea shipping in North America: Understanding the requirements of Atlantic Canadian shippers', Maritime Policy and Management 35(2), 145-158. https://doi.org/10.1080/03088830801956805

Brooks, M.R., Hodgson, J.R. \& Frost, J.D., 2006, 'Short sea shipping on the East Coast of North America: An analysis of opportunities and issues', Dalhousie University, viewed 20 August 2018, from http://maryrbrooks.ca/wp-content/ uploads/2012/03/shortseashipping.pdf.

Brooks, M.R., Puckett, S.M., Hensher, D.A. \& Sammons, A., 2012, 'Understanding mode choice decisions: A study of Australian freight shippers', Maritime Economist and Logistics 14(3), 274-299. https://doi.org/10.1057/mel.2012.8

Ctrack, 2017, Keeping an eye on cargo theft / Ctrack South Africa [WWW Document], viewed 14 September 2018, from https://www.ctrack.com/za/blog/keeping-eyecargo-theft/.

De Jong, G., Vellay, C. \& Houée, M., 2001, 'A joint SP/RP model of freight shipments from the region Nord-Pas-de-Calais', Proceedings of the European Transport Conference, 10-12 September, Homerton College, Cambridge.

Diener-West, M., 2008, Use of the chi-square statistic, John Hopkins University, viewed 14 March 2019, from www.ocw.jhsph.edu/courses/fundepiii/PDFs/ Lecture17.pdf.

Feo, M., Espino, R. \& Garcia, L., 2011, 'An stated preference analysis of Spanish freight forwarders modal choice on the south-west Europe Motorway of the sea', Transport Policy 18(1), 60-67. https://doi.org/10.1016/j.tranpol.2010.05.009

Feo-Valero, M., Garcia-Menendez, L., Saez-Carramolino, L. \& Furio-Prunonosa, S., 2011, 'The importance of the inland leg of containerised maritime shipments: An analysis of modal choice determinants in Spain', Transportation Research Part E: Logistics and Transportation Reviews 47(4), 446-460. https://doi.org/10.1016/j. tre.2010.11.011

García-Menéndez, L. \& Feo-Valero, M., 2009, ‘European common transport policy and short-sea shipping: Empirical evidence based on modal choice models', Transportation Reviews 29(2), 239-259. https://doi.org/10.1080/01441640802357192

García-Menéndez, L., Martínez-Zarzoso, I., De Miguel, D.P., 2004, 'Determinants of mode choice between road and shipping for freight transport: Evidence for four Spanish exporting sectors', Journal of Transport Economics and Policy 38(3), 447-466.

Gupta, O.K., Ali, S.S. \& Dubey, R., 2011, 'Third party logistics', International Journal of Strategic Decision Sciences 2(4), 32. https://doi.org/10.4018/jsds.2011100103

Hess, S. \& Palma, D., 2019, Apollo: A flexible, powerful and customisable freeware package for choice model estimation and application, Journal of Choice Modelling.

Jiang, F., Johnson, P. \& Calzada, C., 1999, 'Freight demand characteristics and mode choice: An analysis of the results of modeling with disaggregate revealed preference data', Journal of Transportation and Statistics 2(2), 149-158.

Kim, H.C., Nicholson, A. \& Kusumastuti, D., 2014, 'Freight transport mode choice and mode shift in New Zealand: Findings of a revealed preference survey', in Sustainable Logistics (Transport and Sustainability) Vol. 6, Emerald Group Publishing Limited, pp. 165-192, https://doi.org/10.1108/S2044-994120140000006007

Konstantinus, A. \& Zuidgeest, M., 2018, 'Freight transport decisions and their considerations in the Southern African Development Community (SADC), in M. Browne (ed.), VREF Urban Freight Conference, p. 35, Gothernburg, Sweden.

Konstantinus, A., Christodoulou, A., Raza, Z., Zuidgeest, M. \& Woxenius, J., 2019, 'Barriers and enablers for short sea shipping in the Southern African Development Community', viewed 14 March 2019, from https://www.mdpi.com/20711050/11/6/1532/pdf.

Lowitt, S., 2017, Cross-cutting logistics issues undermining regional integration across SADC, Trade \& Industrial Policy Strategies (TIPS), Pretoria, South Africa. viewed 14 September 2018, from https://www.tips.org.za/research-archive/trade-and industry/item/3414-cross-cutting-logistics-issues-undermining-regionalindustry/item/3414-cross
integration-across-sadc.

Meers, D., Macharis, C., Vermeiren, T. \& Van Lier, T., 2017, 'Modal choice preferences in short-distance hinterland container transport', Research in Transportation Business and Management 23(June), 46-53. https://doi.org/10.1016/j.rtbm.2017.02.011 
Mitchell, G., 2005, 'Mapping hazard from urban non-point pollution: A screening model to support sustainable urban drainage planning', Journal of Environmental management 74(1), 1-9. https://doi.org/10.1016/j.jenvman.2004.08.002

Murphy, P.R. \& Hall, P.K., 1995, 'The relative importance of cost and service in freight transportation choice before and after deregulation: An update', Transportation Journal 35(1), 30-38, viewed 14 September 2019, from http://www.jstor.org/ page/journal/transportationj/about.html.

Paixão Casaca, A.C. \& Marlow, P.B., 2005, 'The competitiveness of short sea shipping in multimodal logistics supply chains: Service attributes', Maritime Policy and Management 32(4), 363-382. https://doi.org/10.1080/03088830500301469

Pieterse, C., 2018, 'Massive truck theft racket', News24, viewed 14 Septembe 2019, from https://www.news24.com/SouthAfrica/News/massive-truck-theftracket-20180702.

Puckett, S.M., Hensher, D.A., Brooks, M.R. \& Trifts, V., 2011, 'Preferences for alternative short sea shipping opportunities', Transportation Research Part E: Logistics and Transportation Reviews 47(2), 182-189. https://doi.org/10.1016/ j.tre.2010.10.002

Punch, K., 2014, Introduction to social research: Quantitative and qualitative approaches, 3rd edn., Sage Publications, London.

R Core Team, 2016, R: A language and environment for statistical computing, R Foundation for Statistical Computing, Vienna, Austria, viewed 14 July 2018, from https://www.R-project.org/.

Ragoobur, V., 2008, Southern Africa: Doing business and trade in SADC, allAfrica.com [WWW Document], AllAfrica, viewed 15 April 2016, from https://allafrica.com/ stories/200809170880.html.

Rockpoint, 2009, Coastal Shipping and Modal Freight Choice, New Zealand Transport Agency, Wellington, New Zealand, viewed 18 April 2019, from https://treasury. govt.nz/sites/default/files/2017-11/tfr-csmfc-23oct09.pdf.

Rodrigue, J., 2017, The geography of transport systems, 4th edn., Routledge, viewed 18 April 2019, from https://transportgeography.org/.
Russo, F., Musolino, G. \& Assumma, V., 2016, 'Competition between ro-ro and lo-lo services in short sea shipping market: The case of Mediterranean countries', Research in Transportation Business and Management 19(June), 27-33. https:// Research in Transportation Business
doi.org/10.1016/j.rtbm.2016.03.002

SADC, 2013, SADC Regional Infrastructure Development Master Plan [WWW Document], Southern African Development Community, viewed 03 September 2015, from https://www.sadc.int/files/9313/5293/3536/Regional_Infrastructure_

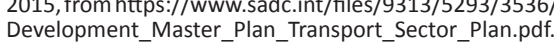

Skondral, A. \& Rabe-Hesketh, S., 2003, 'Multilevel logistic regression for polytomous data and rankings', Psychometrika 68(2), 267-287.

Taylor, M.A.P. \& D'Este, G.M.D., 2003, Concepts of Network Vulnerability: An approach to reliability analysis at the level of National Strategic Transport Networks, Proceeding of the 1st International Symposium on Transportation Network Reliability. pp. 23-44. https://doi.org/10.1108/9781786359544-002

Train, K., 2009, Discrete choice methods with simulation, 2nd edn., Cambridge University Press. https://doi.org/10.1017/CBO9780511753930

Winston, C., 1983. 'The demand for freight transportation: Models and applications' Transport Research. Part A Gen. 17(6), 419-427. https://doi.org/10.1016/0191 2607(83)90162-0

Woxenius, J., Andersson, E., Barthel, F., Troche, G., Sommar, R. \& Trouve, J., 2004, 'A Swedish intermodal transport service based on line-trains serving freight forwarders', in 10th World Conference on Transport Research (WCTR), Istanbul, Turkey, 4-8 July.

Zachcial, M., 2001, Short sea shipping and intermodal paper prepared for the European Conference of Ministers of Transport, OECD Publications, Paris, viewed 18 April 2019, from https://www.researchgate.net/publication/227309242 Short_Sea_Shipping_intermodality_and_parameters_influencing_pricing policies_The_Mediterranean_case.

Zamparini, L., Layaa, J. \& Dullaert, W., 2011, 'Monetary values of freight transport quality attributes: A sample of Tanzanian firms', Journal of Transport Geography 19(6), 1222-1234. https://doi.org/10.1016/j.jtrangeo.2011.01.002 


\section{Appendix 1}

TABLE 1-A1: Data table showing ranking of reliability for respondents 1-4.

\begin{tabular}{lccccccccccccccccc}
\hline Best & 2nd & 3rd & 4th & 5th & 6th & 7th & 8th & Worst & rel_1 & rel_2 & rel_3 & rel_4 & rel_5 & rel_6 & rel_7 & rel_8 & rel_9 \\
\hline 1 & 4 & 2 & 3 & 5 & 6 & 7 & 8 & 9 & 1 & 0 & 0 & 0 & 0 & 0 & 0 & 0 & 0 \\
6 & 7 & 2 & 1 & 5 & 9 & 8 & 4 & 3 & 0 & 0 & 0 & 1 & 0 & 0 & 0 & 0 & 0 \\
5 & 1 & 8 & 4 & 6 & 2 & 3 & 7 & 9 & 0 & 1 & 0 & 0 & 0 & 0 & 0 & 0 & 0 \\
1 & 6 & 5 & 3 & 2 & 8 & 7 & 4 & 9 & 1 & 0 & 0 & 0 & 0 & 0 & 0 & 0 & 0 \\
\hline
\end{tabular}




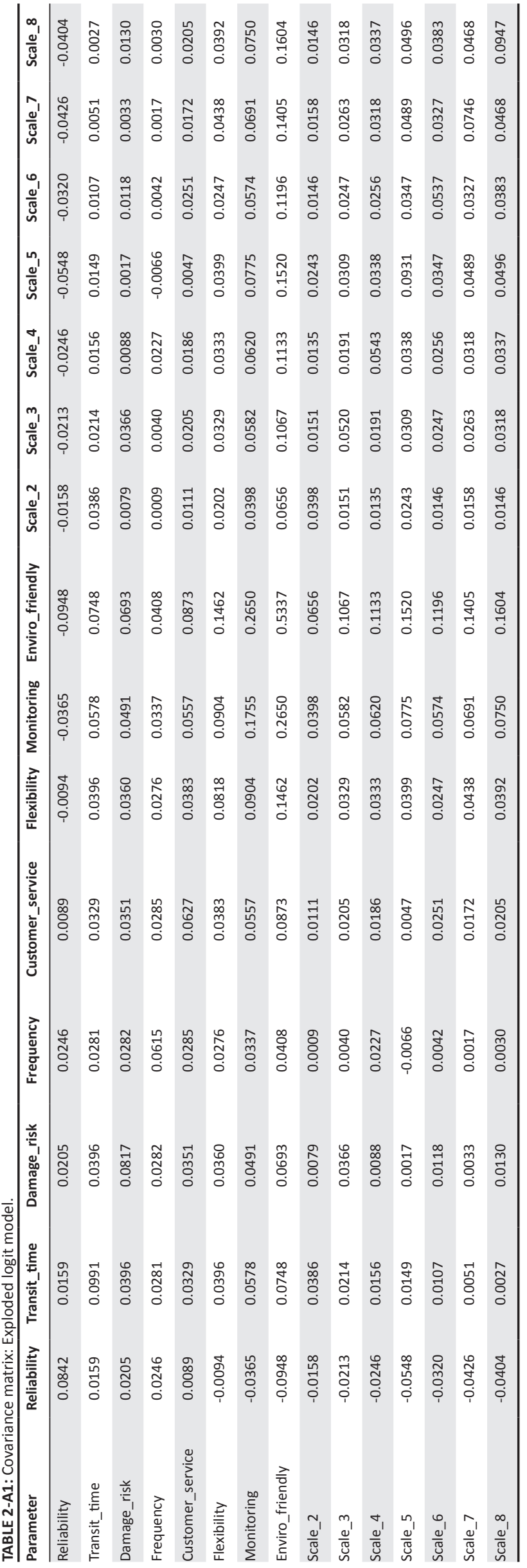

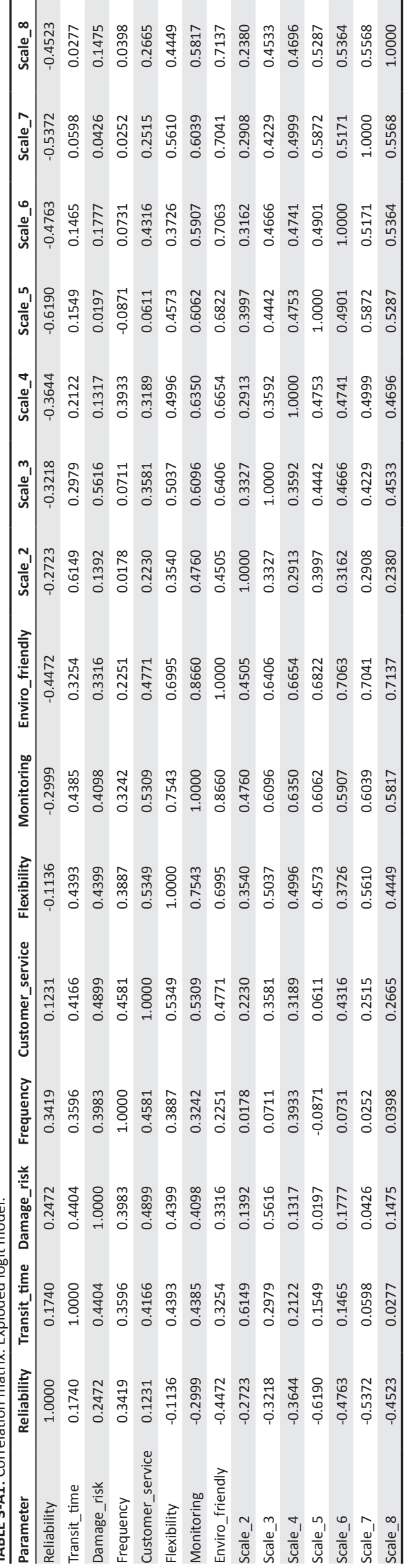

